JURNAL HOLISTIC al-hadis, Vol. 6 , No. 2 (July- December) 2020, 1-9

\title{
FLEKSIBILITAS DAKWAH (Perspektif Sirah Nabi dalam Kitab Ḥayātuṣ Ṣaḥābah)
}

\author{
Apit Hidayat \\ UIN Sultan Maulana Hasanuddin Banten \\ apit.hidayat.student@uinbanten.ac.id
}

\begin{abstract}
Abstrak
Dakwah merupakan sebuah langkah untuk menyiarkan agama Islam. Sehingga hal ini sangatlah diperlukan untuk menyeru umat manusia agar bertaqwa dan beriman kepada Allah Subhanahu wa ta'ala. Dalam berdakwah, terdapat tahapan dan strategi yang harus dimiliki. Selain itu, dakwah bersifat fleksibel, dalam artian tidak mengikat kepada waktu, tempat, obyek, dan hal tertentu lainnya. baik secara perorangan ataupun kepada kelompok tertentu yang harus didakwahi, hal itu wajib dilakukan. Karena jika tidak, maka agama Allah tidak akan berdiri tegak dan banyak umat manusia yang ingkar kepadaNya. Jelaslah hal tersebut sangat miris jika sampai terjadi, sebagaimana umatumat terdahulu yang celaka karena tidak mau beriman kepada-Nya. Kitab Hayātuṣ Șahābah berisi tentang kisah-kisah Rasululullah ketika berdakwah dan juga para sahabat yang melanjutkan dakwah Rasulullah. Dalam kitab ini banyak teladan yang harus dicontoh ketika berdakwah.
\end{abstract}

Kata kunci: dakwah; tahapan dakwah; fleksibilitas dakwah, Ḥayātuṣ Ṣahāābah

\section{Pendahuluan}

Dalam bahasa Arab, Islam berarti damai, aman, selamat, penyerahan, kepatuhan, kesucian dan ketaatan. Jadi Islam adalah suatu ajaran yang membawa kedamaian, keamanan dan keselamatan hidup di dunia dan akhirat. ${ }^{1}$ Islam merupakan agama yang diridhai Allah untuk seluruh umat manusia yang diciptakan-Nya. Sehingga agar Islam tersampaikan kepada seluruh manusia, maka Allah mengutus para Rasul-Nya untuk memberikan pengajaran tentang Islam, dan juga memberitakan kabar gembira dan peringatan tentang hari pembalasan di yaum al-Qiyamah. Dengan demikian, visi Rasul adalah menyeru manusia untuk bertaqwa kepada Allah 幣.

Rasulullah Muhammad merupakan utusan (Rasul) Allah yang terakhir. Tiada lagi nabi dan rasul setelahnya. Muhammad dilahirkan di Makkah pada tanngal 9

\footnotetext{
${ }^{1}$ Syafi' in Mansyur, Metodologi Studi Islam (Serang: FUDA Press, 2009), hlm. 2
} 
Rabi'ul awwal, permulaan tahun dari Peristiwa Gajah. Atau bertepatan pada tanggal 20/22 April tahun 571 Masehi. $^{2}$ Ketika beliau berusia 40 tahun, maka diangkatlah menjadi Rasul oleh Allah 縕. Dan ketika itu pula tugas beliau untuk menyebarkan Agama Allah sudah beliau pikul. ${ }^{3}$

Dalam berdakwah, Rasulullah sangat berhati-hati. Ada tahapan, strategi, dan menejemennya. Bukan hanya itu, beliau juga melihat situasi dan kondisi dalam berdakwah. Kepada siapa, kapan, dan dimana dakwah itu dilakukan. Hal ini tentu saja strategi dan menejemen yang sangat briliant, dan yang paling utama adalah akhlak yang baik dalam menyampaikan agama Allah, karena "Tidak ada paksaan dalam Agama” (Qs. Al-Baqarah [2:256]) ${ }^{4}$

\section{Pengertian Dakwah}

Secara bahasa, dakwah memiliki arti panggilan, seruan, atau ajakan. ${ }^{5}$ Sebagaimana yang tercantum dalam Al-Qur'an Qs. Yusuf [12:33] :

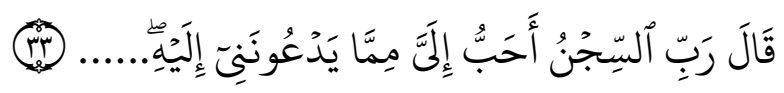

"Yusuf berkata: Wahai Tuhanku, penjara lebih aku sukai daripada memenuhi ajakan mereka....".6

Juga dalam Qs. Yunus [10:25]:

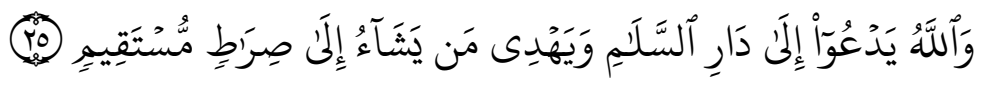

“dan Allah menyeru (manusia) ke Darussalam (surga) dan memberikan petunjuk kepada orang yang Dia kehendaki ke jalan yang lurus (Islam)". ${ }^{7}$

Sedangkan jika ditinjau secara istilah, banyak para ulama dan para ahli yang berpendapat tentang dakwah. H.S.M Nasaruddin Latif mengemukakan bahwa dakwah merupakan setiap usaha atau aktivitas dengan lisan atau tulisan dan lainnya, yang bersifat

\footnotetext{
${ }^{2}$ Syaikh Shafiyyurrahman Al-Mubarakfuri, Ar-Rahiq Al-Makhtum bahtsun fi As-Sirat An-Nabawiyyat 'ala Shaibiha, terj. Agus Suwandi (Jakarta: Ummul Qura, 2018), hlm. 103.

${ }^{3}$ Syaikh Shafiyyurrahman Al-Mubarakfuri, Ar-Rahiq Al-Makhtum bahtsun fi As-Sirat An-Nabawiyyat 'ala Shaibiha, terj. Agus Suwandi, hlm. 134

${ }^{4}$ Tim Penyusun, Al-Hikmah Al-Qur'an dan Terjemahnya (Bandung: CV. Diponegoro, 2014), hlm. 42

${ }^{5}$ A. Rosyad Sholeh, Manajemen Dakwah Islam (Yogyakarta: Suara Muhammadiyah, 2017), hlm. 7

${ }^{6}$ Tim Penyusun, Al-Hikmah Al-Qur'an dan Terjemahnya, hlm. 211

${ }^{7}$ Tim Penyusun, Al-Hikmah Al-Qur'an dan Terjemahnya, hlm. 239
} 
menyeru, mengajak, memanggil manusia lainnya untuk beriman dan mentaati Allah, sesuai dengan garis- garis aqidah dan syariat serta akhlak Islamiyah. ${ }^{8}$

Sedangkan menurut Letjen H Sudirman mengemukakan bahwa dakwah merupakan usaha untuk merealisasikan ajaran Islam di dalam kenyataan hidup seharihari, baik bagi kehidupan seseorang maupun kehidupan masyarakat sebagai seluruh tata hidup bersama, dalam rangka pembangunan bangsa dan umat manusia untuk memperoleh keridhaan Allah. ${ }^{9}$

Dari pengertian-pengertian yang dikemukakan di atas, maka dakwah adalah mengajak orang atau masyarakat untuk beriman dan bertaqwa kepada Allah. Dengan demikian, prisip dakwah adalah amar ma'ruf nahi munkar.

\section{Tahapan Dakwah}

Pada pentas sejarah, dakwah Nabi dibagi ke dalam dua periodisasi yakni periode Makkah dan Madinah. Kedua periode ini memiliki karakter dan strategi masing-masing, hal ini dapat dilihat dari sejauh mana hasil yang telah dicapai oleh Nabi pada periode Makkah dan Madinah. Para sejarawan memberikan kategorisasi bahwa dakwah Nabi di Makkah bercirikan dengan misi penanaman aqidah terhadap umat, sementara di Madinah lebih cenderung terhadap pembangunan sosial kemasyarakatan dan hukum. ${ }^{10}$

Selain itu, dakwah Rasulullah memiliki tahapan-tahapan terrtentu yang juga merupakan strategi dalam berdakwah. Tahap pertama, Rasulullah berdakwah secara sembunyi-sembunyi kurang lebih selama 3 tahun. Dakwah tahap ini dilakukan di Makkah, yaitu dikalangan suku Quraisy yang pada masa itu masih menyembah berhala. tentu saja membuthkan tekad baja untuk mendobrak kejahilan tersebut. Sehingga generasi pertama yang nabi dakwahi adalah orang terdekat beliau, yaitu anggota keluarga dan para sahabatnya. ${ }^{11}$

Pada tahap ke dua, Rasulullah mengumpulkan semua keluarganya yaitu kalangan bani Hasyim. Sebagaimana perintah Allah :

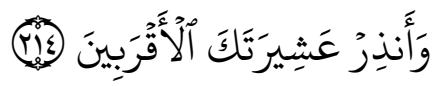

\footnotetext{
${ }^{8}$ HS.M Nasaruddin Latif, Teori dan Praktek Da'wah Islamiyah (Jakarta: Penerbit Firma, 1971), hlm. 11

${ }^{9}$ Letjen H. Sudirman, Problematika Da'wah Islam di Indonesia, Forum Da'wah (Jakarta: Pusat Dakwah Islam Indonesia, 1972), hlm. 47

${ }^{10}$ St. Nasriah, "DAKWAH PADA MASA NABI MUHAMMAD SAW (Studi Naskah Dakwah Nabi Muhammad Pada Periode Madinah)", Jurnal Dakwah: Tabligh, Vol. 17, No. 2 (Desember 2017), hlm. 15 ${ }^{11}$ Syaikh Shafiyyurrahman Al-Mubarakfuri, Ar-Rahiq Al-Makhtum bahtsun fi As-Sirat An-Nabawiyyat 'ala Shaibiha, terj. Agus Suwandi, hlm. 147
} 
"Dan berilah peringatan kepada keluargamu yang terdekat." (Qs. Asy-Syu'ara [26: 214]) ${ }^{12}$

Ayat tersebut merupakan perintah pertama dari Allah untuk dakwah secara terangterangan kepada para keluarga Rasulullah Dalam tahap ini, terdapat beberapa anggota keluarga yang menolak dengan keras, ingin mencegah/ menghalagi, dan ada pula yang mendukung penuh jalan dakwah Rasulullah .

Melalui proses yang panjang, kemudian turun ayat yang memerintahkan Rasulullah untuk berdakwah kepada semua penduduk Makkah secara terang-terangan.

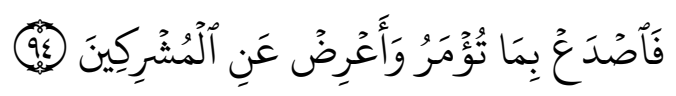

"Maka sampaikanla olehmu secara terang-terangan segala apa yang diperintahkan (kepadamu) dan berpalinglah dari orang-orang yang musyrik." (Qs. Al-Hijr [15: 94) ${ }^{13}$

Dari ayat tersebutlah menjadi dasar Rasulullah untuk menyiarkan dakwah Islam, menyeru para musyrikin Quraisy untuk beriman kepada Allah. Mendobrak kemungkaran dan menyerang berbagai khurafat dan kebohongan syirik, menyebutkan kedudukan berhala dan hakikatnya yang sama sekali tidak memiliki nilai.

\section{Kitab Ḥayātuṣ Șahāābah}

Kitab Ḥayātuṣ Șaḥābah ditulis oleh Syaikh Muhammad Yusuf Al-Kandahlawi (1335 H/1917 M - 1384 H/1965 M). beliau merupakan seorang ulama sekaligus da'i serta mubaligh kelahiran Kandhla, Uttar Pradesh, India. Beliau tumbuh besar dalam lingkungan yang wara' lagi agamis, asuhan ibu yang shalihah, serta didikan para syaikh dan ulama. Ketika dewasa, ia berbaiat kepada ayahnya, Syaikh Muhammad Ilyas, yang notabene pendiri Jama'ah Tabligh, hingga kemudian ditunjuk sebagai penggantinya.

Kitab Hayātuṣ Ṣaḥābah merupakan kitab yang berisi kisah-kisah para sahabat Rasulullah Dalam pengantar kitab ini, yang diampaikan oleh Abu Al-Hasan AnNadwi, beliau mengatakan bahwa orang pertama di zamannya (abad ke-20 M) yang menulis kitab tentang kisah para sahabat adalah Syaikh Muhammad Yusuf AlKandahlawi. Kitab ini termasuk ke dalam pembahasan tentang dakwah dan terbiyah

\footnotetext{
12 Tim Penyusun, Al-Hikmah Al-Qur'an dan Terjemahnya, hlm. 376

${ }^{13}$ Tim Penyusun, Al-Hikmah Al-Qur'an dan Terjemahnya, hlm. 267
} 
Islam. Ini menunjukkan bahwa begitu besar kecintaan Syekh Yusuf terhadap Sirah Nabawiyyah dan kisah para Sahabat Radiyallahu anhum. ${ }^{14}$

Kitab ini menghadirkan sistematika penulisan yang mudah dan gamblang, tanpa pengulangan keragaman riwayat. Penulis menggunakan riwayat yang terkuat, terinci, dan yang paling mewakili tema yang sedang dibahas. Penulis menjadikan sembilan belas bab dalam buku ini sebagai panggung kehidupan para sahabat r.a. dalam berbagai situasi: Tentang kekuatan iman mereka kepada Allah dan Rasul-Nya; Tentang pengorbanan, kontribusi, dan kedermawanan mereka; Tentang keberanian dan perjuangan mereka; Tentang akhlak, sifat, dan sikap mereka ketika menghadapi kesulitan, dan lain-lain. Untuk melukiskan hal tersebut, Penulis menggali ribuan nash dari kitab hadis, tafsir, dan sejarah yang bisa menjelaskan gagasannya dan mewujudkan maksudnya. Selanjutnya, dengan bagus sekali ia menyusunnya dalam bab yang sesuai. Alhasil, terciptalah lukisan yang indah, lengkap dengan gerak dan kehidupan. Dari sini, kita bisa mengenal para sahabat Rasulullah s.a.w. sebagai teladan mulia dalam akhlak serta agama, dan panutan yang baik dalam ilmu dan amal.

\section{Fleksibilitas dakwah}

Fleksibilitas, dalam Kamus Besar Bahasa Indonesia (KBBI) memiliki arti . kelenturan, penyesuaian diri secara mudah dan cepat; keluwesan; ketidakcanggungan. ${ }^{15}$ Secara istilah, banyak pakar dan para ahli dibidangnya mendefinisinkan arti kata fleksibilitas. Dalam pandangan ilmu kesehatan/kedokteran fleksibilitas memiliki arti luas gerak satu persendian atau beberapa persendian. ${ }^{16}$

Dalam pandangan sosial, fleksibilitas merupakan kemampuan beradaptasi dan bekerja dengan efektif dalam situasi yang berbeda dengan berbagai individu atau kelompok. ${ }^{17}$ Sedangkan dalam pandangan ilmu Psikologi, fleksibilitas adalah menghubungi saat ini sepenuhnya sebagai manusia yang sadar, dan berdasarkan kepada

\footnotetext{
${ }^{14}$ Syaikh Muhammad Yusuf Al-Kandahlawi, Hayātuṣ Șaḥābah (Kehidupan Para Sahabat), terj. Nur Cholis al-Adib, Jilid ke-1 (Yogyakarta: Ash-Shaf, 2017), hlm. v

${ }^{15}$ KBBI online, "Arti Kata Fleksibilitas" dalam https://kbbi.web.id/fleksibilitas/diakses 30 November 2020

${ }^{16}$ Teguh Budiman, "Pengertian Fleksibilitas" dalam https://docplayer.info/47619117-Fleksibilitaspengertian-fleksibilitas.html/2017/ diakses 30 November 2020

${ }^{17}$ Naila Amalia, “Apa yang dimaksud dengan Fleksibilitas" dalam https://www.dictio.id/t/apa-yangdimaksud-dengan-fleksibilitas/1512/ 6 Februari 2016/ diakses 30 November 2020
} 
apa yang diberikan situasi, mengubah atau bertahan dalam perilaku dalam melayani nilainilai yang dipilih. ${ }^{18}$

Dari beberapa pengertian fleksibilitas menurut sudut pandang disiplin ilmu yang berbeda, maka pembahasan dalam artikel ini penulis mengambil salah satu pengertian fleksibilitas menurut pandangan sosial. Yaitu, fleksibilitas merupakan kemampuan beradaptasi dan bekerja dengan efektif dalam situasi yang berbeda dengan berbagai individu atau kelompok. Dalam hal ini berfokus pada kegiatan dakwah, bahwa seorang $d a^{\prime} i$ harus bersifat fleksibel, tidak mengikat kepada salah satu hal saja tetapi harus bisa beradaptasi dengan lingkungan maupun antar manusia baik individu maupun kelompok.

Penulis mengangkat pembahasan fleksibilitas dakwah (Perspektif Sirah Nabi dalam kitab Ḥayātuṣ Șahābah) karena ketika membaca kitab tersebut bahwa Rasulullah dalam berdakwah begitu fleksibel dan bisa beradaptasi dengan sangat baik. Beliau berdakwah bukan hanya kepada kaum tertentu saja, melainkan kepada semua kalangan, semua tempat, dan situasi. Beliau berdakwah kepada perorangan dan kelompok, juga berdakwah di pasar, di perjalanan, ketika perang, dan situasi lainnya.

Walaupun secara umum, kitab ini menceritakan tentang kisah-kisah para sahabat Rasulullah ketika memeluk Islam. Namun penulis hanya mengambil bagian kecil dari kitab ini yang menceritakan tentang dakwah Rasulullah yang menurut penullis sangat fleksibel dan hal itu diikuti pula oleh para sahabat Rasulullah dalam melanjutkan dakwah beliau.

Pada bagian ini, penulis akan mengklasifikasikan dakwah Rasulullah yang memiliki fleksibilitas. Diambil dari beberapa bab dalam kitab Ḥayātuṣ Șaḥābah.

\section{Dakwah Kepada Orang Tertentu}

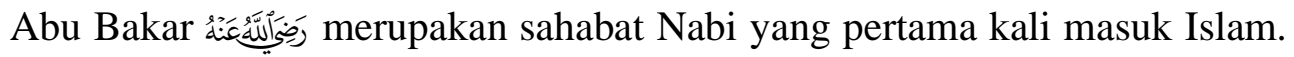

Beliau juga merupakan teman dekat Nabi ketika zaman jahiliyah. Sehingga Abu Bakar sangat mengenal sifat jujur beliau, sifat amanah beliau, watak beliau yang sangat baik, dan kemuliaan akhlak Rasulullah yang tidak mungkin berbicara bohong tentang makhluk apalagi tentang sang Pencipta.

Nabi berdakwah kepada Abu bakar secara personal. Dalam sebuah riwayat dari Ibnu Ishaq bahwa Abu Bakar mendatangi Rasulullah dan berkata: "Benarkah yang

\footnotetext{
${ }^{18}$ Danif, “Apa yang dimaksud dengan Fleksibilitas" dalam https://www.dictio.id/t/apa-yang-dimaksuddengan-fleksibilitas/1512/ 8 Februari 2016/ diakses 30 November 2020
} 
dikatakan orang-orang Quraisy wahai Muhammad, bahwa engkau meninggalkan tuhantuhan kami, menganggap bodoh akal kami, dan mengkafirkan nenek moyang kami?" Maka Rasulullah bersabda:"Ya! Sesungguhnya aku adalah utusan Allah dan juga NabiNya. Dia telah mengutusku untuk menyampaikan risalah dari-Nya dan mengajakmu (beriman) kepada Allah dengan kebenaran. Demi Allah sesungguhnya hal ini benar adanya. Wahai Abu Bakar, aku mengajakmu (agar beriman) kepada Allah semata, tiak ada sejutu bagi-Nya. Juga agar kamu tidak menyembah selain Dia, dan agar kamu senantiasa taat kepada-Nya.” Kemudian Abu Bakar Masuk Islam. ${ }^{19}$

Dalam kisah tersebut, penulis mengambil pelajaran bahwa dalam berdakwah, seorang $d a$ ' $i$ harus dikenal baik oleh orang yang akan didakwahi agar tiada keraguan dalam orang tersebut untuk masuk Islam. Sebagaimana Abu Bakar yang merupakan sahabat dekat Rasulullah yang mengenal Rasulullah dengan baik.

Selain Abu Bakar, masih banyak lagi para sahabat yang Rasulullah dakwahi secara personal/perorangan. Diantaranya yaitu, Umar bin Khattab, Utsman bin 'Affan, Ali bin Abu Thalib, 'Amr bin 'Abasah, Khalid bin Sa'id bin 'Ash, Dhimad, Hushain (Ayah 'Imran), Mu'awiyah bin Haidah, 'Adi bin Hatim, Dzul Jausyan Adh-Dhababi, Basyir bin Khashashiyah, Abu Quhafah dan orang yang tidak

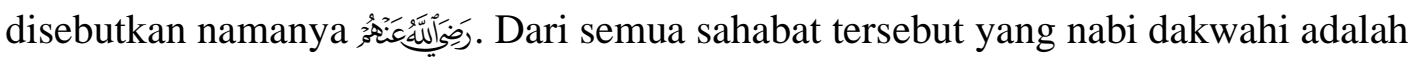
yang bersedia masuk Islam dan berbeda kisahnya satu sama lain. Adapun yang Nabi dakwahi tidak mau masuk Islam adalah Abu Jahal dan Walid bin Mughirah.

\section{Dakwah Kepada Sekelompok Orang}

Ketika Rasulullah mengemban tugas untuk menyeru manusia untuk beriman kepada Allah, maka beliau melaksanakan tugas terrsebut denggan penuh kesabaran. Dakwah bukanlah tugas yang mudah, apalagi berhadapan dengan sekelompok orang yang memiliki kedudukan dan pengaruh besar terhadap sebuah kabilah, atau kelompok tersebut.

Dalam sebuah riwayat dari Ibnu Jarir menerangkan bahwa seorang laki-laki dari Bani 'Abdi ad-Dar, Abu al-Bakhtari dari kabilah Bani Asad, Aswad bin Mutthalib bin Asad, Zam'ah bin Aswad, Walid bin Mughirah, Abu Jahal bin Hisyam,

\footnotetext{
${ }^{19}$ Syaikh Muhammad Yusuf Al-Kandahlawi, Hayātuṣ Șaḥābah (Kehidupan Para Sahabat), terj. Nur Cholis al-Adib, hlm. 54-74
} 
Abdullah bin Abu Umayyah, Umayyah bin Khalaf, 'Ash bin Wa'il, Nubaih bin Hajjaj As-Sahmi, dan Munabbih bin Hajjaj as-Sahmi berkumpul setelah terbenamnya matahari dari belakang Ka'bah. Salah seorang dari mereka berkata kepada yang lain, "Utuslah seseorang untuk memanggil Muhammad, lalu bicaralah kalian dengannya dan bantahlah ia, sehingga kalian terhindar dari celaan orang-orang sehubungan dengannya." Kemudian mereka mengirim utusan kepada beliau dengan pesan "orang-orang terhormat dari kabilahmu telah berkumpul untuk berbicara denganmu." Maka Rasulullah cepat-cepat menemui mereka, sedangkan beliau mengira bahwa mereka telah berubah pikiran (hendak menerima Islam).

Kemudian Rasulullah duduk dihadapan mereka, lalu mereka berkata, "Hai Muhammad! Kami telah mengirim utusan kepadamu agar kami terhindar dari celaan sehubungan denganmu. Demi Allah! Sesungguhnya kami tidak mengetahui seorang pun dikalangan bangsa Arab yang berbuat keburukan terhadap kaumnya seperti apa yang kamu perbuat terhadap kaummu. Sungguh, kamu telah mencaci nenek moyang kami, mencela agama kami, menganggap bodoh akal pikiran kami, mencaci tuhantuhan kami, memecah belah kesatuan, dan tidak tersisa satu keburukan pun tanpa kamu perbuat terhadap kami. Jika kamu membawa perkara baru ini karena harta, kami akan mengumpulkan harta kami untukmu, sehingga kamu menjadi orang yang paling banyak hartanya diantara kami. Jika kamu hanya ingin mencari kehormatan di antara kami, kami akan menjadikanmu pemimpin kami. Jika kamu ingin menjadi raja, kami akan menjadikanmu sebagai raja kami. Jika yang membuatmu melakukan semua itu adalah seorang jin yang menurutmu telah menguasai dirimu, mungkin inilah yang terjadi, maka kami akan membelanjakan harta kami untuk mengusahakan pengobatan agar dapat menyembuhkanmu, atau kami tidak sanggup lagi mengusahakan penyembuhan untukmu."

Kemudian Rasulullah berssabda "semua yang kalian sebutkan itu tidak ada padaku, aku membawa kepada kalian (agama) yang aku bawa ini bukanlah untuk mencari harta dari kalian, bukan pula mencari kehormatan pada kalian, bukan pula ingin menjadi raja kalian. Akan tetapi Allah mengutusku kepada kalian sebagai seorang Rasul, menurunkan kitab suci kepadaku, memerintahkan kepadaku agar menjadi pembawa kabar gembira dan pemberi peringatan bagi kalian. Maka aku sampaikan risalah Tuhanku kepada kalian dan menginginkan kebaikan bagi kalian. 
Jika kalian menerima (agama) yang aku bawa kepada kalian, maka hal itu akan menjadi kemujuran bagi kalian di dunia dan akhirat. Namun jika kalian menolaknya, maka aku akan bersabar menjalani perintah Allah, hingga Allah menetapkan hukumnya antara aku dan kalian."

Kemudian para petinggi kabilah Quraisy itu meminta pembuktian kepada Rasulullah tentang kerasulannya. Mereka menyuruh Rasulullah untuk meminta kepada Allah agar memindahkan dua gunung besar yang menghimpit kota Makkah, menghidupkan nenek moyang mereka, menciptakan tangga yang mmenjulang ke langit, meruntuhkan langit, menurunkan malaikat untuk bersaksi bahwa Muhammad adalah seorang rasul, bahkan meminta agar Allah menampakkan diri-Nya dihadapan mereka. Kemudian Rasulullah menjawab "aku tidak akan melakukannya. Aku bukanlah orang yang meminta hal-hal seperti itu kepada Tuhanku. Aku diutus bukan dengan hal-hal seperti itu. Akan tetapi Allah mengutusku sebagai pembawa kabar gembira dan pemberi peringatan. Maka jika kalian menerima (agama) yang aku bawa kepada kalian, maka hal itu akan menjadi kemujuran bagi kalian di dunia dan akhirat. Namun jika kalian menolaknya, maka aku akan bersabar menjalani perintah Allah, hingga Allah menetapkan hukumnya antara aku dan kalian." 20

Dari kisah tersebut, kita mendapat pelajaran bahwa tujuan dakwah bukan untuk mendapat harta, meraih kedudukan dan khormatan, ataupun pujian dari orang lain. Melainkan benar-benar untuk menyiarkan dan mengajak umat manusia untuk taat kepada Allah. Dan juga dalam dakwah banyak cobaan yang akan dihadapi, tetapi Rasulullah membeli contoh kepada kita agar selulu tegar dan kuat. Selain itu, dakwah tidak bersifat memaksa, melainkan cukup membawa keabar gembira dan juga memberi peringatan.

Selain dakwah kepada kaum Quraisy, Rasulullah juga berdakwah ketika musim haji tiba. Beliau mnyiarkan agama Allah kepada setiap kabilah. Diantaranya adalah kabilah Bani 'Amr dan Bani Muharib, Bani 'Abs, kabilah Kindah, kabilah Bani Ka'b, Bani Kalb, Bani Hanifah, Bakr bin Wai'il, Kabilah di Mina, kabilah Bani Syaiban, kabilah Aus dan Khazraj.

\section{Dakwah di Pasar}

\footnotetext{
${ }^{20}$ Syaikh Muhammad Yusuf Al-Kandahlawi, Hayātuṣ Șaḥābah (Kehidupan Para Sahabat), terj. Nur Cholis al-Adib, hlm. 79-82
} 
Dalam sebuah riwayat Ahmad, dari Rabi'ah bin 'Ibad, dari Bani Dil, yang dulunya pernah mengalami masa Jahiliyah, aku melihat Rasulullah di pasar Dzul Majaz. Beliau berseru "Wahai manusia! Ucapkanlah Lāilāha illallāh niscaya kalian berjaya." Orang-orang pun berkumpul disekitarnya. Sedangkan dibelakangnya ada seorang laki-laki berwajah tampan, matanya juling, dan rambutnya berjambul dua. Ia berkata, "Sungguh, ia seorang pendusta yang berpindah agama!" orang itu mengikuti beliau kemanpun beliau pergi. Dan laki-laki tersebut adalah Abu Lahab. ${ }^{21}$

Pasar merupakan tempat berkumpul banyak orang, sehingga tidak heran jika Nabi berdakwah di pasar, karena untuk mengajak manusia yang ada di tempat tersebut untuk beriman kepada Allah. Pasar Dzul Majaz merupakan pasar yang berlokasi di dekat pasar Ukaz yaitu di daerah Nejaz. Pasar ini buka dari tanggal 1-7 Dzulhijjah. $^{22}$

\section{Kesimpulan}

Dakwah Rasulullah memiliki tahapan, strategi dan manajemen yang sangat baik. Selain itu, Nabi memiliki fleksibilitas dakwah, sehingga beliau dakwah kepada siapa saja, kapan saja, dan dimana saja. Dalam kitab Ḥayātuṣ Șahāābah yang mencakup kisah-kisah para sahabat yang masuk Islam karena dakwah dari Nabi, menerangkan pula kisah dakwah Nabi kepada perorangan, kelompok, di pasar, dan situasi lainnya. sehingga dapat disimpulkan bahwa nabi dalam berdakwah memiliki fleksibilitas yang perlu dicontoh dalam dakwah.

\section{DAFTAR PUSTAKA}

Mansyur, Syafi' in. Metodologi Studi Islam. Serang: FUDA Press, 2009.

Al-Mubarakfuri, Syaikh Shafiyyurrahman. Ar-Rahiq Al-Makhtum bahtsun fi As-Sirat An-Nabawiyyat 'ala Shaibiha, terj. Agus Suwandi. Jakarta: Ummul Qura, 2018. Tim Penyusun. Al-Hikmah Al-Qur'an dan Terjemahnya. Bandung: CV. Diponegoro, 2014.

\footnotetext{
${ }^{21}$ Syaikh Muhammad Yusuf Al-Kandahlawi, Hayātuṣ Șahābah (Kehidupan Para Sahabat), terj. Nur Cholis al-Adib, hlm. 105

22 Portal Satu, "Pasar-pasar yang Pernah disinggahi Nabi Muhammad", dalam http://portalsatu.com/read/Blog/pasar-pasar-yang-pernah-disinggahi-nabi-muhammad-39023.html/ 25 Desember 2017/ diakses 30 November 2020
} 
Sholeh, A. Rosyad. Manajemen Dakwah Islam. Yogyakarta: Suara Muhammadiyah, 2017.

Latif, Nasaruddin H.S.M. Teori dan Praktek Da'wah Islamiyah. Jakarta: Penerbit Firma, 1971.

Letjen H. Sudirman. Problematika Da'wah Islam di Indonesia, Forum Da'wah. Jakarta: Pusat Dakwah Islam Indonesia, 1972.

Nasriah, St. "DAKWAH PADA MASA NABI MUHAMMAD SAW (Studi Naskah Dakwah Nabi Muhammad Pada Periode Madinah)", Jurnal Dakwah: Tabligh, Vol. 17, No. 2. (Desember 2017).

Al-Kandahlawi, Yusuf Syaikh Muhammad. Hayātuṣ Șahābah (Kehidupan Para Sahabat), terj. Nur Cholis al-Adib, Jilid ke-1. Yogyakarta: Ash-Shaf, 2017.

KBBI online, “Arti Kata Fleksibilitas” diakses 30 November 2020. https://kbbi.web.id/fleksibilitas/

Budiman, Teguh "Pengertian Fleksibilitas" diakses 30 November 2020. https://docplayer.info/47619117-Fleksibilitas-pengertian-fleksibilitas.html

Amalia, Naila. “Apa yang dimaksud dengan Fleksibilitas” diakses 30 November 2020. https://www.dictio.id/t/apa-yang-dimaksud-dengan-fleksibilitas/1512

Danif. “Apa yang dimaksud dengan Fleksibilitas” diakses 30 November 2020. https://www.dictio.id/t/apa-yang-dimaksud-dengan-fleksibilitas/1512

Portal Satu. "Pasar-pasar yang Pernah disinggahi Nabi Muhammad". diakses 30 November 2020. http://portalsatu.com/read/Blog/pasar-pasar-yang-pernahdisinggahi-nabi-muhammad-39023.html/ 25 Desember 2017/ 